\title{
Forecasting of Sheep and Goat Meat Export from India
}

\author{
C.A. Nimbalkar*, Swati D. Shinde, A.J. Nalawade and M.B. Gund \\ Mahatma Phule Krishi Vidyapeeth, Rahuri 413722, Dist. Ahmednagar, Maharashtra, India \\ *Corresponding author
}

Keywords

Sheep and goatmeat, Export, ARIMA, Time series, Forecasting

Article Info

Accepted:

12 June 2019

Available Online:

10 July 2019

\section{A B S T R A C T}

The purpose of this paper is to study the current trend of export of sheep and goat meat from India and forecasting of the same for next five years by using the time series modelling. Four different Autoregressive Integrated Moving Average (ARIMA) models were fitted to annual sheep and goat meat export (quantity) from India using data records from 1990-1991 to 2017-18. Using goodness of fit criteria i.e. Akaike Information Criterion (AIC) and Bayesian information criterion (BIC), the model with order $(0,0$, 2) was considered as most suitable model out of other orders $(2,1,0),(4,0$, $0)$ and $(1,4,0)$. The forecasting of future annual meat export quantity in leading five years was done using by the best model with higher accuracy Annual sheep and goat meat export from India in five leading years is expected to be having increasing trend observed with positive growth rate $(3.80 \%)$.

\section{Introduction}

In Indian economy livestock is an important constituent particularly in the agricultural sector. Livestock provides milk, meat, skin, manure, wool, draft powder and other valuable products. India is on the top in cattle and buffalo population, second in goat, third in sheep and seventh in Poultry according to livestock census. In rural part of the country where over 15-20 per cent families are landless and about 80 per cent of the land holders belong to the category of small and marginal farmers (Savita et al., 2017) so, products of livestock are very important contributor to socio-economic development of farmer and nation also.

Goats and sheep constitute a very important species of livestock in India, mainly due to of their short generation intervals, higher rates of prolificacy and the ease with which the goats as also their products viz., meat, wool and milk can be marketed. They are considered to be very important for their contribution to the development of rural zones and people. The global demand for livestock products is an opportunity for India to increase its exports. Meat is one of the important products of this. Meat exported from India is risk-free, lean, 
nutritious and competitive priced meat. It has resulted in consistent, high compound growth rate in the export volumes.

Meat is a rich source of valuable proteins, vitamins, minerals, micronutrients and fats. It also supplies Omega 3 fatty acid and conjugated linoleic acid (Devi et al., 2014).

India is largest exporters of sheep and goat meat to the world. The country has exported total (sheep and goat) 22,060.15 metric tonnes meat to the world for the worth of 871.08 crores/ 130.17 Million USD during the year 2016-17. The major export destinations in 2016-17 are United Arab Emirates, Saudi Arabia, Qatar, Kuwait and Oman (APEDA). There is huge potential in this sector for economic development of the country through increasing exports.

Therefore, the study was undertaken to perform time series modeling for export of sheep and goat meat in India by using data from 1990-91 to 2017-18and to forecast the export of sheep and goat meat for next five years.

\section{Materials and Methods}

\section{Data}

The data of annual meat export and production of sheep and goat in India for the period from 1990-91 to 2017-18were obtained from Basic Animal Husbandry Statistics reports maintained by Department of Animal Husbandry, Dairying and Fisheries, Government of India (Anonymous, 2015).

\section{Statistical analysis}

Trend analysis fits a particular type of trend line or curve to a time series data. Trend analysis was carried out by fitting the linear, quadratic and exponential form.
Linear trend: $\mathrm{Y}_{\mathrm{t}}=\mathrm{a}+\mathrm{bt}$

Quadratic: ${ }_{\mathrm{t}}=a+b \mathrm{t}+\mathrm{ct}^{2}$

Exponential growth trend: ${ }_{\mathrm{t}}=a b^{\mathrm{t}}$

Where, ${ }^{\mathrm{t}_{\mathrm{t}}}=$ Quantity at time $\mathrm{t}$

$\mathrm{a}=$ intercept

$\mathrm{b}$ and $\mathrm{c}=$ slope parameters

$\mathrm{t}=$ time period

Growth rate; $\mathrm{CGR}=($ Antilog b-1 $) * 100$

To find out the best suited trend was carried out on the basis of $\mathrm{R}^{2}$, Mean square error, Root mean square error and Mean absolute per cent error. Similar works reported by Pal (2017) for price forecasting.

Autoregressive Integrated Moving Average (ARIMA) models introduced by Box-Jenkins (1970) was used for the time series modelling and forecasting of sheep and goat meat export quantity for the five leading years. Before applying the ARIMA the time series should be checked for stationarity. ARIMA models include autoregressive (AR) terms, differencing operations and moving average (MA) terms with their respective order $\mathrm{p}, \mathrm{d}$ and $\mathrm{q}$, respectively. Differencing is a technique by which non-stationary time series is transformed into stationary time series. Differencing eliminates trend and seasonality and consequently stabilizes the mean of the time series. The non-seasonal ARIMA ( $p, d$, q) model for the predicted value of meat export quantity (y) in period $t$ based on data observed up to period t-1was used as follows.

$y_{t}=\mu+\varphi_{1} y_{t-1}+\cdots+\varphi_{p} y_{t-p}+e_{t}-\theta_{1} e_{t-1}-\cdots-\theta_{q} e_{t-q}$

Where $\mu$ is the constant, $\mathrm{Y}_{\mathrm{t}}$ and $\mathrm{e}_{\mathrm{t}}$ are the actual values and random error at time $t$, respectively. $\varphi_{\mathrm{k}}$ is the Auto regressive (AR) coefficient at lag $\mathrm{k},{ }_{\mathrm{k}}$ is the Moving average (MA) coefficient at lag k, and 
$e_{t-k}=y_{t-k}-\hat{y}_{t-k}$ is the forecast error that was made at period $\mathrm{t}-\mathrm{k}$. The parameters $\mathrm{p}, \mathrm{d}$ and $\mathrm{q}$ are small integers and the weights (coefficients) may be positive or negative. This model takes into account the non-zero autocorrelation between the successive values of the time series data. The main stages in fitting Box-Jenkins forecasting model are as follows:

\section{Model identification}

Using autocorrelation function (ACF), partial autocorrelation function (PACF), degree of differencing and appropriate autoregressive and moving average terms are determined.

\section{Estimation}

Generally parameters of ARIMA were estimated according to the orders considered in the model. The values of $p, d$ and $q$ in the model and their statistical significance were judged by t-test.

\section{Diagnostic checking}

It consists of evaluating the adequacy of the estimated model.

The residuals of ACF and PACF considered random when all their ACF's are within the limits.

The null hypothesis that autocorrelation coefficient is equal to zero is judged by LjungBox statistic (Q- statistic) (Ljung and Box, 1970). If Q-statistics for residuals of ARIMA model is not significant then the fitted ARIMA model is appropriate, otherwise not.

\section{The minimum Akaike Information Coefficient (AIC)}

The minimum value of AIC is used to determine both the differencing order $(\mathrm{d}, \mathrm{D})$ required to attain stationarity and the appropriate number of AR and MA parameters (Shruthi, 2015).

\section{Forecasting}

Final model was used to forecast meat export for five leading years. The relative measure of forecast accuracy is descripted by mean absolute percentage error (MAPE) as descripted by Pankratz (1983).

Four ARIMA models i.e. Model $(0,0,2)$; Model (2, 1, 0), Model (4, 0, 0) and Model (1, 4,0 ) were tested in this study for modelling of time series data of sheep and goat meat export from India and subsequently best model was used for forecasting purpose.

For identifying best model, Akaike Information Criterion (AIC) and Bayesian information criterion (BIC) were used as follows.

$\mathrm{AIC}=2 \mathrm{k}-2 \ln (\mathrm{L})$

$\mathrm{BIC}=\ln (\mathrm{n}) \mathrm{k}-2 \ln (\mathrm{L})$

Where, $\mathrm{k}$ is the number of free parameters to be estimated, $\mathrm{n}$ is the number of data points, $\ln (\mathrm{L})$ is natural logarithm of the maximized value of the likelihood function of the model. The model with lowest value of AIC and BIC was considered as best model.

All statistical analyses were done using Forecast command in SPSS 22 software.

\section{Results and Discussion}

The annual trend of export of sheep and goat meat from India over the year 1990-91 to 2017-18was shown in Figure 1. It was clearly observed from the figure that the trend of the sheep and goat meat is not linear over the years. The growth rate of meat export quantity during this period was about 3.85 per cent. 
Table.1 Error measures of fitted trends in meat export quantity (q)

\begin{tabular}{|l|c|c|c|c|c|}
\hline & MSE & RMSE & MAPE & $\mathbf{R}^{2}$ & Adj. $\mathbf{R}^{\mathbf{2}}$ \\
\hline Linear & 86388614 & 9294.548 & 28.71 & $23.03 \%$ & 0.200 \\
\hline Quadratic & 88209468 & 9391.99 & 26.46 & $24.43 \%$ & 0.184 \\
\hline Exponential & 0.048871 & 0.22107 & 12.43 & $27.93 \%$ & 0.251 \\
\hline
\end{tabular}

Table.2 AIC, BIC and Ljung-Box test statistic for four ARIMA model fitted to annual meat export data

\begin{tabular}{|l|c|c|c|c|}
\hline Model Fit statistics & $\mathbf{( 0 , 0 , 2}$ & $\mathbf{( 2 , 0 , 1 )}$ & $\mathbf{( 4 , 0 , 0 )}$ & $\mathbf{( 1 , 0 , 4 )}$ \\
\hline AIC & 1.473 & 1.503 & 1.506 & 1.540 \\
\hline BIC & 1.665 & 1.743 & 1.794 & 1.876 \\
\hline Ljung-Box (Q Statistic) & 16.186 & 12.530 & 12.055 & 11.671 \\
\hline p-value & 0.440 & 0.639 & 0.602 & 0.555 \\
\hline Log L & -15.886 & -15.293 & -14.339 & -13.802 \\
\hline
\end{tabular}

Table.3 Parameters estimates of the best fitted ARIMA model $(0,0,2)$ meat export

\begin{tabular}{|l|r|r|r|r|}
\hline Variable & Coefficient & \multicolumn{1}{c|}{ SE } & \multicolumn{1}{c|}{ t } & \multicolumn{1}{|c|}{ p value } \\
\hline Constant & 0.036049 & 0.028596 & 1.260648 & 0.2201 \\
\hline MA(1) & -0.28129 & 4528.344 & $-6.21 \mathrm{E}-05$ & 1 \\
\hline MA(2) & -0.71871 & 16390.78 & $-4.38 \mathrm{E}-05$ & 1 \\
\hline SIGMASQ & 0.169925 & 261.0979 & 0.000651 & 0.9995 \\
\hline
\end{tabular}

Table.4 Forecasted values of sheep and goat meat export quantity (q) with $95 \%$ confidence interval

\begin{tabular}{|c|c|c|c|}
\hline Year & Forecast & LCL & UCL \\
\hline $\mathbf{2 0 1 8 - 1 9}$ & 23599.3 & 8732.07 & 52750.73 \\
\hline $\mathbf{2 0 1 9 - 2 0}$ & 23817.32 & 7282.35 & 60000.43 \\
\hline $\mathbf{2 0 2 0 - 2 1}$ & 25048.5 & 7596.2 & 63414.64 \\
\hline $\mathbf{2 0 2 1 - 2 2}$ & 25976.84 & 7877.72 & 65764.9 \\
\hline $\mathbf{2 0 2 2 - 2 3}$ & 26939.59 & 8169.69 & 68202.26 \\
\hline
\end{tabular}

Table.5 t-test for actual and forecasted values of sheep and goat meat export quantity (q)

\begin{tabular}{|l|c|c|}
\hline & Sheep and goat meat quantity (q) (actual) & Forecast \\
\hline Mean & 14336.24 & 14237.8 \\
\hline Variance & 108000000 & 33142630 \\
\hline Observations & 28 & 28 \\
\hline t Stat & 0.070824 & \\
\hline p-value & 0.94406 & \\
\hline
\end{tabular}


Fig.1 Annual export of sheep and goat meat in India from 1990-91 to 2017-18

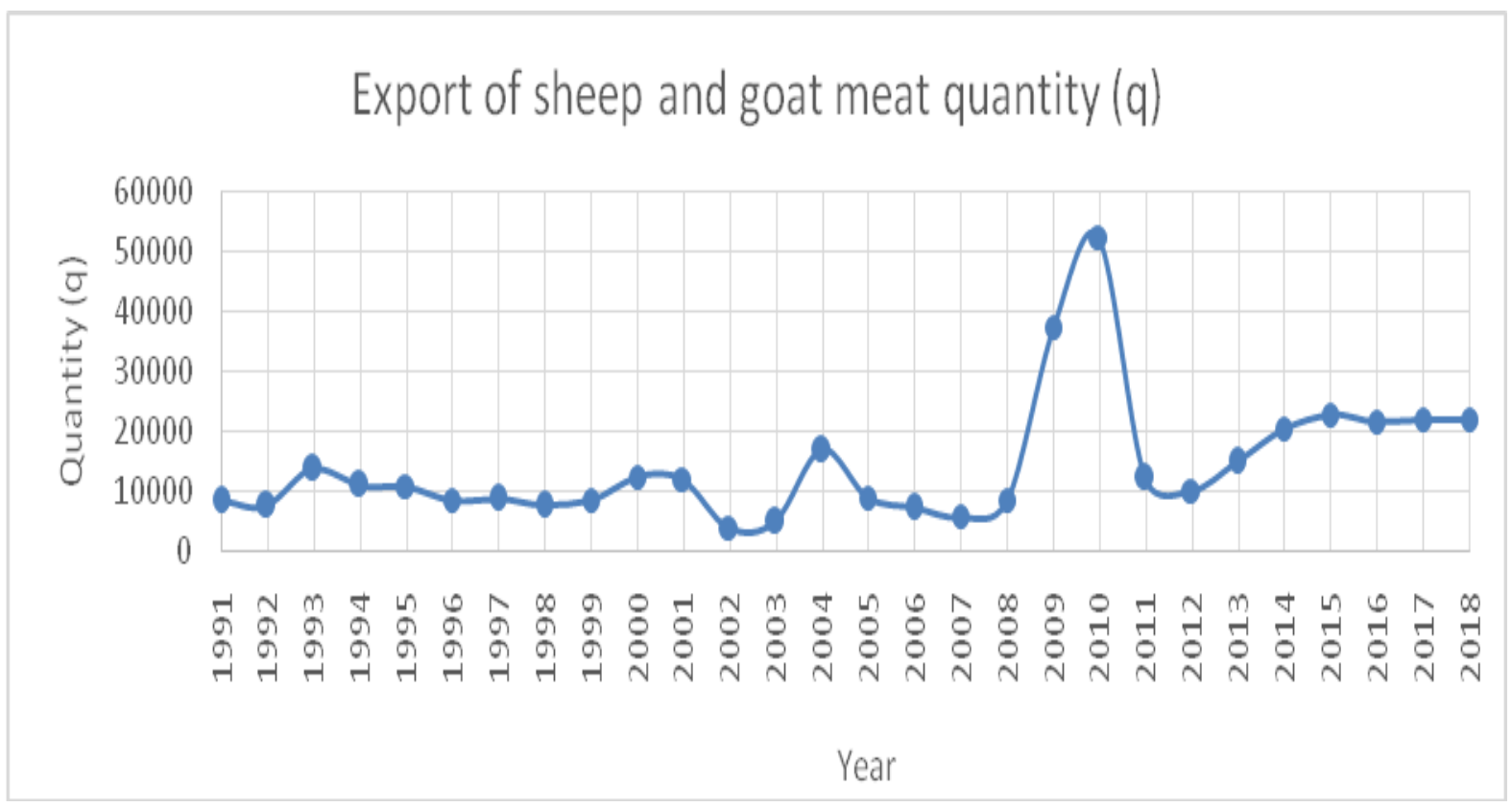

Fig.2 ACF and PACF of residuals of fitted ARIMA model for meat export

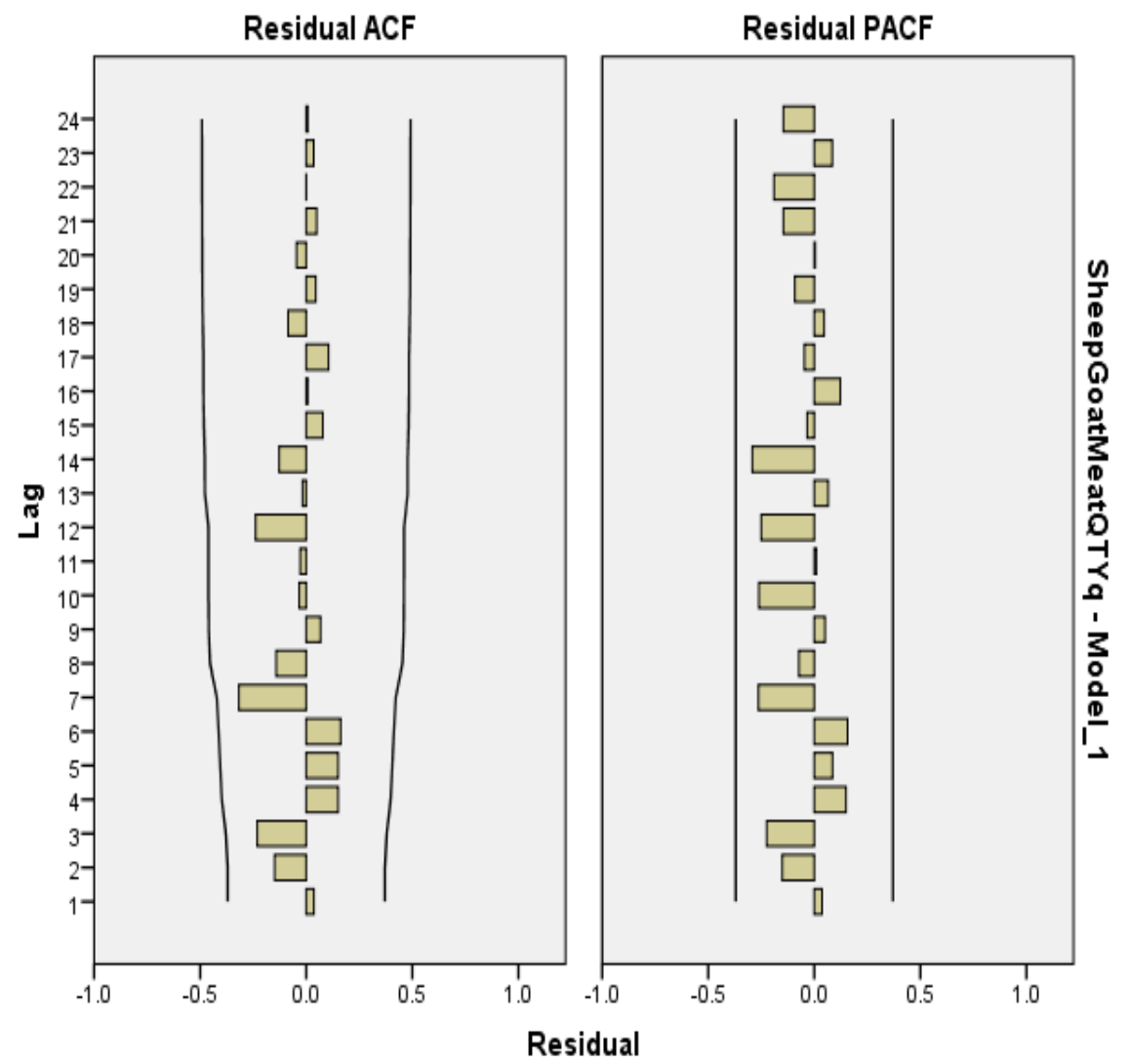


Fig.3 Actual and forecasting of sheep and goat meat export quantity (q) from India over the year 1991-92 to 2022-23.

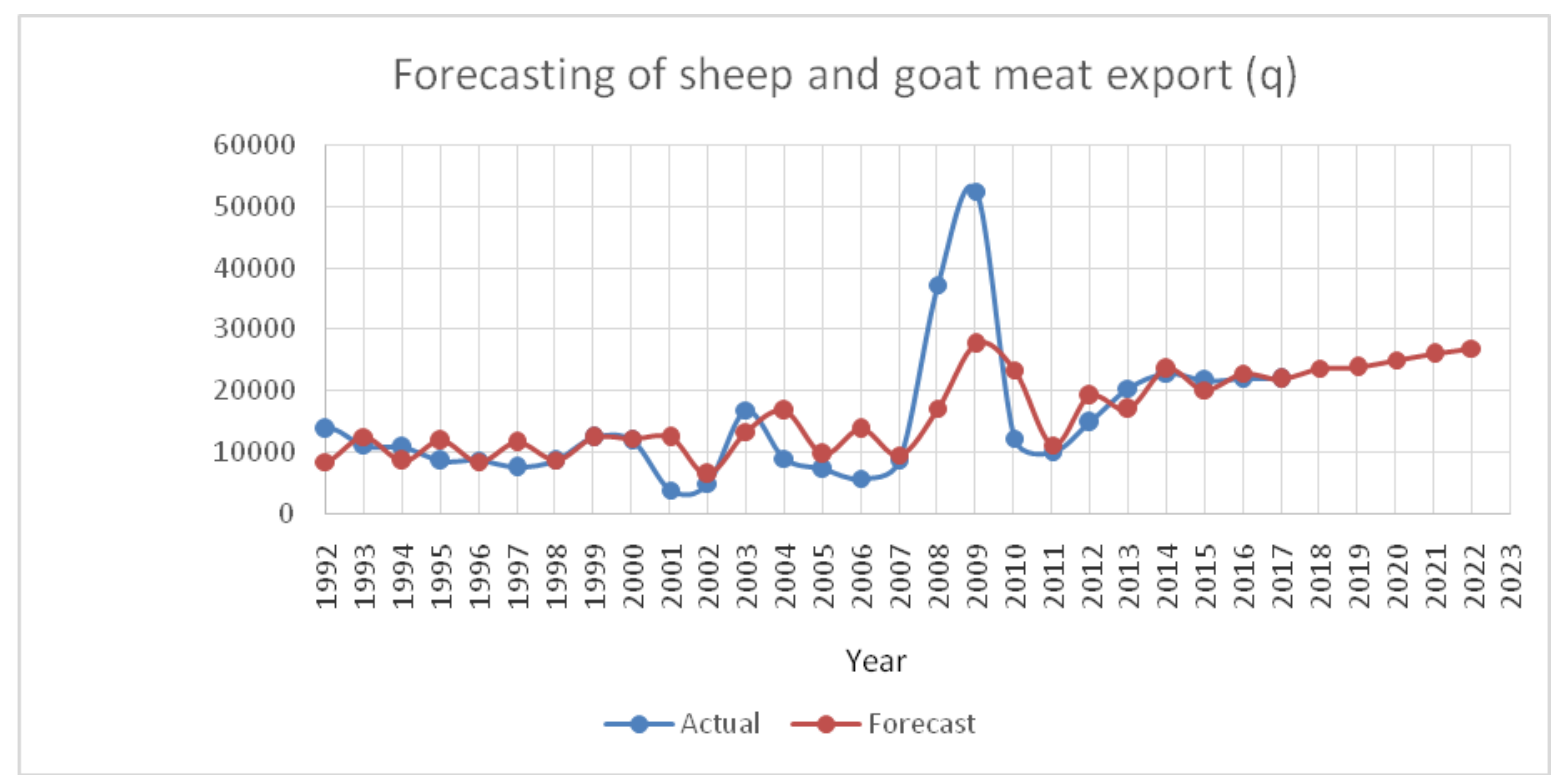

In this study the trend analysis was used to forecast the sheep and goat meat export quantity from India. Different forms of trends fitted to meat export of sheep and goat data for the year 1990-91 to 2017-18. Linear, quadratic and exponential trends were used for trend studies and forecasting purpose.

Among the different trends fitted for meat export quantity (q), the exponential trend has minimum MSE and RMSE but its $\mathrm{R}^{2}$ was very low $27.9 \%$ (Table 1) which indicates that the exponential trend was not also best suited for this data.

\section{Model identification}

Under ARIMA model, time series modelling of export of sheep and goat meat was done. The stationary series was necessary for application of the models and this was achieved by differencing by first order. The identification of orders of $p$ and $q$ was done by using Auto Correlation Function (ACF) and Partial Auto Correlation Function (PACF) which indicated that the order of $p$ and $q$ can at most be 1 .

\section{Model estimation and verification}

The different statistics of the corresponding model after fitting of four model with their AIC and BIC values are shown in Table 2 . Considering the criteria of AIC and BIC values; the lowest values of $\mathrm{AIC}$ and $\mathrm{BIC}$ was observed for the ARIMA model $(0,0,2)$. Therefore, this model was considered as a best model for time series modelling of annual sheep and goat meat export quantity. Also, the Ljung-Box statistic (Q-statistic) for this model was non-significant hence, the model $(0,0,2)$ was more appropriate.

Estimates of parameters of ARIMA model ( 0 , $0,2)$ are given in Table 3 . Model verification was done by examining the auto correlations and partial auto correlations of the residuals (Figure 2). The ACF and PACF of the residuals indicated good fit of the ARIMA model $(0,0,2)$.

\section{Forecasting with ARIMA model}

ARIMA model provides the best weighted average forecasts for a single time series 
(Rahulamin and Razzaque, 2000). The forecasts for sheep and goat meat export quantity during 2018-19 to 2022-23 are presented in Table 4. It was observed that there will be increasing trend of annual meat export in next five years, with annual growth rate in meat export quantity from India was $3.80 \%$. During 2017-18 the annual export of sheep and goat meat from India was 21906.51 (q) and forecasted value for same year is 21918.53 (q) which indicate the accuracy of the fitted model. The export of sheep and goat meat expected to be 26939.59 (q) in 2022-23. It emphasizes the need for increase in the sheep and goat meat production in India in order to get agricultural development (Fig. 3).

The t-statistic value (0.0708) for the difference between forecast by ARIMA and actual values with p-value $=0.94406$, showing non-significant difference (Table 5) indicated that this ARIMA $(0,0,2)$ model was the best fit to the forecast of meat export quantity (q).

On the basis of goodness of fit criteria i.e. AIC and BIC, ARIMA $(0,0,2)$ model was found the most suitable model among the four different models tested for time series modelling of sheep and goat meat export quantity from India The low value of MAPE indicated higher accuracy of forecasting of sheep and goat meat export data.

The increasing trend was observed from the forecasting of annual sheep and goat meat export data from India in five leading years with very low annual growth.

\section{References}

Anonymous, 2012. 19 ${ }^{\text {th }}$ Livestock Census, 2012. Department of Animal Husbandry, Dairying and Fisheries, Ministry of Agriculture \& Farmers Welfare, Government of India. http://dahd.nic.in/
Anonymous, 2015. Basic Animal Husbandry and Fisheries Statistics. 2015. Department of Animal Husbandry, Dairying and Fisheries, Ministry of Agriculture \& Farmers Welfare, Government of India. http://dahd.nic.in/sites/default/files/ BAH_\%26_FS_Book.pdf Retrieved on $10^{\text {th }}$ December 2016.

Anonymous, 2016. Wool production estimates during 2014-15. Government of India. https://community.data.gov.in/ Retrieved on $10^{\text {th }}$ December 2016.

Box, G.E.P. and Jenkin, G.M. 1970. Time series of analysis. Forecasting and Control, San Francisco, Holden Day, 553p. California, USA.

Devi, Subramaniam Mohana, Vellingiri Balachandar, Sang In Lee, and In Ho Kim. 2014. An outline of meat consumption in the Indian population a pilot review. Korean J. Food Sci. Anim. Resour. 34(4): 507-515.

Ljung, G. and Box, G., 1978. On a Measure of Lack of Fit in Time Series Models, Biometrika, 65,297-303.

Makridakis, S. and Hibbon, M., 1979. Accuracy of forecasting: an empirical investigation. Journal of Royal Statistical Society, A 41(2): 97-145.

Pal V., 2017. Price forecasting of brinjal and chilli (green) -a statistical evaluation. M.Sc. Thesis. Anand Agricultural University, Anand, Gujarat.

Pankratz, A. 1983. Forecasting with univariate Box-Jenkins Models: Concept and cases, John Wiley \& Sons, New York.

Rahulamin, M.D. and Razzaque, M.A., 2000. Autoregressive integrated moving average modeling for monthly potato prices in Bangladesh. Journal of Financial Management and Analysis. 13(1): 74-80.

Savita, Jain V. K., Singh H.P. and Lal S., 2017. Current Status of Livestock 
Products in India and Their Trade Performance. International Journal of Current Microbiology and Applied Sciences. 6(6): 504-508

Shruthi, J., 2015. An analysis of price forecasting techniques for onion and tomato crops. Unpublished master's thesis, University of Agricultural Sciences, Dharwad, Karnataka (India). www.apeda.gov.in

\section{How to cite this article:}

Nimbalkar, C.A., Swati D. Shinde, A.J. Nalawade and Gund, M.B. 2019. Forecasting of Sheep and Goat Meat Export from India. Int.J.Curr.Microbiol.App.Sci. 8(07): 1365-1372.

doi: https://doi.org/10.20546/ijcmas.2019.807.163 